\title{
The Effect of Pyloromyotomy on Serum and Luminal Gastrin in Infants with Hypertrophic Pyloric Stenosis
}

\author{
John R. Wesley, M.D., Richard Fiddian-Green, M.D., Larry D. Roi, Ph.D., \\ Piyush C. Kothary, M.S., William H. Weintraub, M.D., Arnold G. Coran, M.D., \\ AND Aaron I. Vinik, M.D.
}

Section of Pediatric Surgery and Department of Surgery, and the Department of Biostatistics, School of Public Health, Mott Children's Hospital, and University of Michigan Medical School, Ann Arbor, Michigan 48109

Presented at the Annual Meeting of the Association for Academic Surgery, Great Gorge, New Jersey, November 11-14, 1979

\begin{abstract}
Previous studies of the pathogenesis of congenital hypertrophic pyloric stenosis (CHPS) have implicated immunoreactive gastrin, although no consistent relationship has been demonstrated. In this study we have examined the effect which pyloromyotomy has on serum and luminal gastrin concentration after a mechanical and protein stimulus. Seventeen infants were examined preoperatively, and 1 week after pyloromyotomy. On each occasion, samples of serum and gastric contents were collected from fasting infants. Sixty cubic centimeters of water was placed into the stomach and further samples collected 20 min later. The water was then aspirated and replaced by $60 \mathrm{cc}$ of $10 \%$ peptone broth and a third set of samples collected after $20 \mathrm{~min}$. All samples from each patient were analyzed for immunoreactive gastrin in the same assay. Pyloromyotomy did not alter fasting serum gastrin $(119.3 \mathrm{pg} \pm 11.9$ preop vs $164.7 \pm 29.9$ postop $)$ nor did it alter the gastrin response to water. Pyloromyotomy decreased the incremental serum gastrin response to peptone broth $(66.6 \pm 16.9$ preop vs $18.9 \pm 11.7$ postop $)$. Luminal gastrin concentration was not significantly affected by pyloromyotomy. When the pre- and postoperative serum gastrin increments for water and peptone were plotted against the fasting gastrin levels, an inverse relationship was apparent which was statistically significant by regression analysis. Seen in this way, intragastric water and peptone have a dual effect on serum gastrin; a rise if the fasting serum gastrin concentration is low; a fall or lesser rise if the fasting serum gastrin concentration is high. The data suggest that the direction and magnitude of serum gastrin response to intragastric water or peptone is set by the fasting level, and is independent of pyloromyotomy.
\end{abstract}

Recent efforts to determine the etiology of congenital hypertrophic pyloric stenosis (CHPS) have focused on the possible role of gastrin, first suggested by Dodge in 1970 when he reported pyloric tumors in puppies following injection of adult female dogs with pentagastrin during pregnancy [2]. Since then, studies by several investigators have focused on the differences between serum gastrin in fasting infants with pyloric stenosis and normal fasting infants. These studies have resulted in conflicting data (Table 1). Some investigators have found significant differences between mean serum gastrin levels in fasting infants with CHPS and levels in fasting controls, and concluded that elevated serum gastrin is related to CHPS. Other investigators have reported no sig- nificant differences, and concluded the opposite. Except for Moazam and her colleagues, no group of investigators has examined the gastrin response to feeding in infants with CHPS. The present study was designed to evaluate the effect of pyloromyotomy on the serum and intraluminal gastrin levels after giving water and a standard protein meal in order to determine how pyloromyotomy alters the gastrin response to feeding and whether this alteration might be a factor in the etiology of the disorder.

\section{MATERIALS AND METHODS}

During the 22 months between December 1977 and October 1979, 17 infants with CHPS were evaluated. There were 15 males and 2 females, ranging in age from 3 to 
TABLE 1

Fasting Serum Gastrin Levels in Congenital Hypertrophic Pyloric Stenosis

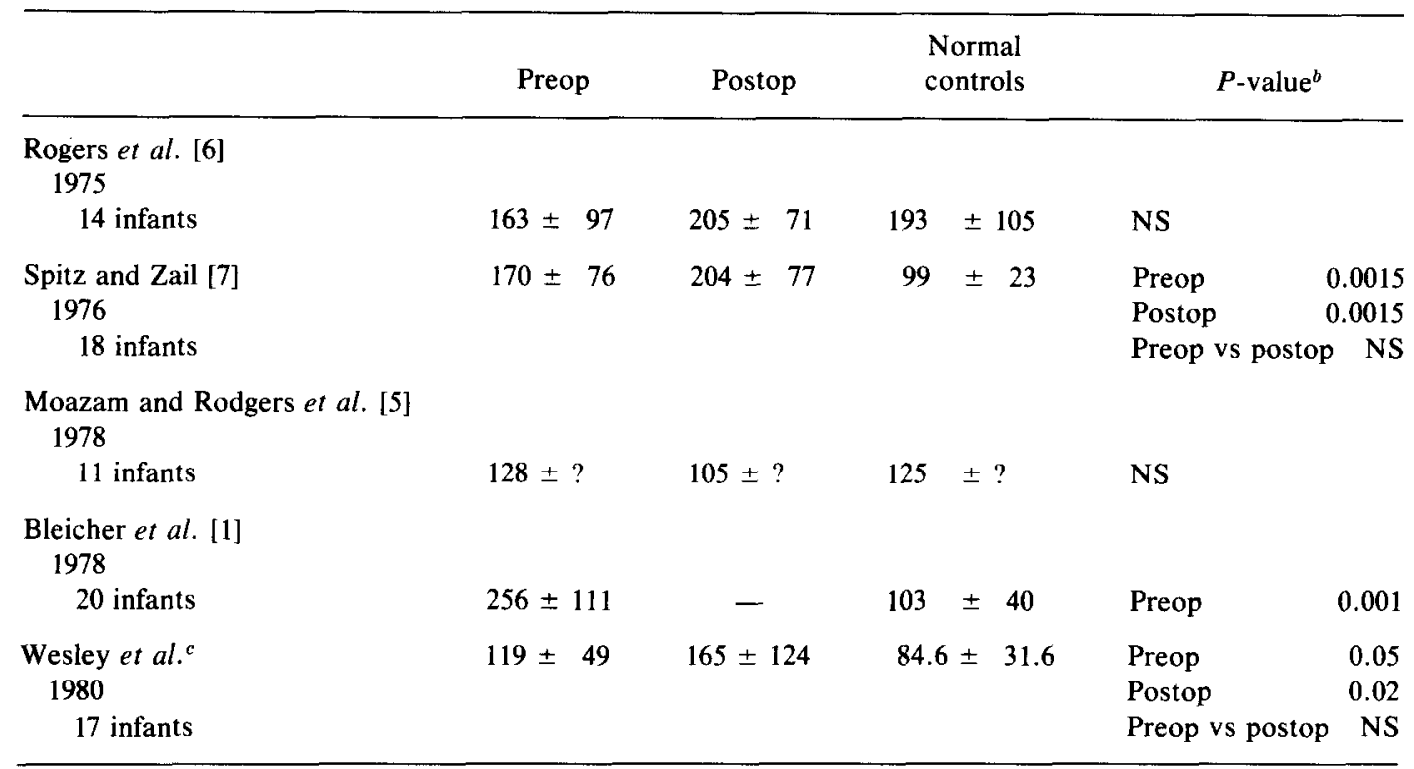

a Summary of data reported in five studies of infants with CHPS comparing preop with postop, and normal infants with preop and postop. All values are expressed as $\mathrm{pg} / \mathrm{ml}$ with $\mathrm{SD}$ except Moazam and Rodgers et al. where confidence limits were not reported. Normal infants were in the same age range as those with CHPS.

${ }^{b}$ Preop vs postop; normals vs pre- and postop.

c Present reported series.

11 weeks at the time of diagnosis. Body weights ranged from 1.9 to $4.4 \mathrm{~kg}$ with an average of $3.6 \mathrm{~kg}$. All infants were rehydrated as necessary prior to the study, and any electrolyte abnormalities were corrected. A nasogastric tube was placed for gastric decompression, and each infant was fasted for 2 to $4 \mathrm{hr}$ prior to the preoperative study. Two milliliters of venous blood and an aliquot of gastric fluid were drawn in the fasting state, $20 \mathrm{~min}$ after placement of $60 \mathrm{cc}$ of tap water in the stomach, and again $20 \mathrm{~min}$ after placement of $60 \mathrm{cc}$ of a standard protein meal consisting of $10 \%$ peptone broth. The stomach was aspirated clear between each $60 \mathrm{cc}$ of fluid instillation. Blood samples were immediately placed on ice, and the serum separated and frozen within $20 \mathrm{~min}$ to $1 \mathrm{hr}$ for later gastrin determination. The gastric fluid was immediately boiled to deactivate pepsin and pepsinogen, and frozen for later gastrin measurement. In addition, the $\mathrm{pH}$ of each gastric sample was measured by standard $\mathrm{pH}$ electrode. An identical evaluation was performed 1 to 2 weeks postoperatively after the infant was eating a normal diet and gaining weight. Each infant was fasted for 3 to $4 \mathrm{hr}$ prior to the follow-up study.

Serum gastrin levels were also determined in 17 control patients between 3 and 11 weeks of age after a $6 \mathrm{hr}$ fast (14 males and 3 females). These were healthy infants undergoing elective herniorrhaphy or circumcision.

This study protocol was approved by the University of Michigan Human Use Committee and informed consent was obtained from the parents of each infant.

Pre- and postoperative serum and gastric juice samples from each patient were analyzed at the same time for gastrin by radioimmunoassay according to methods previously described $[4,9]$. The antiserum used recognizes the biologically active carboxyl terminus of all molecular forms of 
TABLE 2

CHPS

Mean Serum Immunoreactive Gastrin ${ }^{a}$

\begin{tabular}{lccccc}
\hline & Fasting & $60 \mathrm{cc}$ Water & $\begin{array}{c}\text { Water } \\
\text { - fasting }\end{array}$ & 60 cc Peptone & $\begin{array}{c}\text { Peptone } \\
- \text { fasting }\end{array}$ \\
\hline Preop & $119.3 \pm 11.9$ & $133.0 \pm 20.2$ & $17.0 \pm 14.3$ & $182.6 \pm 21.1$ & $66.6 \pm 16.9$ \\
$\begin{array}{l}\text { Postop } \\
P \text {-value }\end{array}$ & $164.7 \pm 29.9$ & $145.8 \pm 20.8$ & $-18.9 \pm 14.1$ & $183.6 \pm 26.3$ & $18.9 \pm 11.7$ \\
& NS* & NS & $0.065^{* *}$ NS & NS & $0.010^{* * *}$ \\
\hline
\end{tabular}

${ }^{a}$ Mean serum gastrin response $20 \mathrm{~min}$ after water and peptone instillation expressed as absolute values and as increments (positive or negative change) between water or peptone and fasting levels. Results are expressed as $\mathrm{pg} / \mathrm{ml} \pm \mathrm{SE} ; n=17$.

* paired $t$ test, two sided.

** paired $t$ test, one sided.

gastrin. Measurements were determined in duplicate and the average recorded as the value of gastrin for each specimen. The within assay coefficient of variation was $1.97-6.44 \%$ for concentrations of human serum gastrin between 25 and $1000 \mathrm{pg} / \mathrm{ml}$.

Statistical analysis was primarily accomplished using two sample or paired $t$ tests. In several analyses of data from the CHPS patients, a repeated measures design with covariate adjustment was utilized [8].

\section{RESULTS}

The mean serum gastrin level in fasting infants with CHPS was not changed significantly by pyloromyotomy (Table 2). When compared with 17 normal infants in the same age range, both preoperative and postoperative pyloric infants had significantly higher mean fasting gastrin levels (normal $84.6 \pm 7.9 \mathrm{pg} / \mathrm{ml}$; preop pyloric
$119.3 \pm 11.9, \quad P<0.05 ;$ postop pyloric $164.7 \pm 29.9, \quad P<0.02$ ). Mean serum gastrin levels measured $20 \mathrm{~min}$ after instillation of $60 \mathrm{cc}$ of tap water (distention stimulus) into the stomach of infants with CHPS showed no significant difference from fasting levels, and no significant difference when preoperative and postoperative levels were compared. Mean serum gastrin levels measured $20 \mathrm{~min}$ after instillation of $60 \mathrm{cc}$ of $10 \%$ peptone broth (distention plus protein meal stimulus) showed no significant difference between preoperative and postoperative levels (Table 2).

When the increments (positive or negative change) between fasting and distention stimulus (water - fasting) or fasting and distention plus protein stimulus (peptone - fasting) were compared, the preoperative water increment showed no significant difference from the postoperative increment. How-

\section{TABLE 3}

CHPS

Mean Luminal ImMUnoreactive Gastrin ${ }^{a}$

\begin{tabular}{lccccc}
\hline & & & Water & & Peptone \\
& Fasting & $60 \mathrm{cc}$ Water & - fasting & $60 \mathrm{cc}$ Peplone & $\begin{array}{c}\text { fasting } \\
\text { Preop }\end{array}$ \\
\hline Postop & $42.4 \pm 15.8$ & $1.8 \pm 1.8$ & $-40.5 \pm 14.9$ & $99.1 \pm 15.6$ & $56.7 \pm 20.0$ \\
$P$-value & $23.8 \pm 8.3$ & $3.5 \pm 1.9$ & $-20.4 \pm 7.4$ & $89.3 \pm 10.2$ & $65.5 \pm 13.4$ \\
& NS & NS & NS & NS & NS \\
\hline
\end{tabular}

${ }^{a}$ Mean luminal gastrin response 20 min after water and peptone instillation expressed as absolute values and as increments (positive or negative change) between peptone and fasting levels. Results are expressed as $\mathrm{pg} / \mathrm{ml} \pm \mathrm{SE} ; n=11$. 
TABLE 4

CHPS

pH AND VOLUME RECOVERED ${ }^{a}$

\begin{tabular}{lcccc}
\hline & Fasting $\mathrm{pH}$ & Water $\mathrm{pH}$ & Peptone $\mathrm{pH}$ & Volume recovered \\
\hline Preop & $3.2 \pm 0.29$ & $3.3 \pm 0.23$ & $6.9 \pm 0.12$ & $58.6 \pm 1.5$ \\
Postop & $3.8 \pm 0.58$ & $3.8 \pm 0.27$ & $6.9 \pm 0.10$ & $31.6 \pm 3.5$ \\
$P$-value & NS & NS & NS & $<0.001$ \\
\hline
\end{tabular}

${ }^{a}$ Mean gastric fiuid recovery and $\mathrm{pH} 20 \mathrm{~min}$ after water and peptone instillation. Results are expressed as units $\pm \mathrm{SE} ; n=11$.

ever, the preoperative peptone increment was reduced postoperatively, and the difference was statistically significant (Table 2).

Pre- and postoperative fasting intraluminal gastrin levels showed no statistically significant difference, nor did the preoperative response to $60 \mathrm{cc}$ of water or $10 \%$ peptone broth show any significant difference from the postoperative response, both with respect to actual values or increments (Table 3). Likewise, the preoperative $\mathrm{pH}$ of the intraluminal fluid in the fasting pyloric infant showed no statistically significant difference from the postoperative determination; this finding was also true after instillation of water or peptone broth (Table 4). The volume recovered after instillation of either water or peptone was nearly complete preoperatively and about two-thirds complete postoperatively (Table 4). There was no significant effect of this pre- and postoperative volume difference on either the serum or luminal gastrin as analyzed using repeated measures design with covariate adjustment.

When the increment of serum gastrin was plotted against fasting serum gastrin concentration, an inverse relationship was found for both water and peptone broth. Figs. 1 and 2 display these plots and the best fitting regression line for the 34 preand postoperative increments as a group. Both regression lines fit well with respective $r$ values of 0.766 and 0.307 . One point in Fig. 1 was 11 SD higher than the regression line and was judged to be an outlier and was not used in the regression analysis.
After adjusting for preoperative and postoperative effect and individual patients in a repeated measures analysis with a covariate, the regression effect between the increment and fasting level was even stronger in the same direction. This relationship was not statistically different for the preoperative, postoperative, or combined categories with respect to water or peptone.

\section{DISCUSSION}

In our patients, serum gastrin in the fasting state is unchanged by pyloromyotomy. This is in agreement with the findings of Rogers et al. [6], Spitz and Zail [7], and Moazam et al. [5]. When compared to healthy fasting infants, however, our patients had significantly higher fasting serum gastrin levels both pre- and postoperatively. This agrees with the findings of Spitz and Zail [7] and Bleicher et al. [1] but contrasts with the findings of Rogers et al. [6] and Moazam and co-workers [5] who reported no significant differences between serum gastrin levels in fasting infants with CHPS and age-matched controls. These conflicting results might be explained by technical factors, such as the length of the fasting state as suggested by Spitz and Zail [7] or by the small sample size of the studies coupled with the high variability of the serum gastrin levels. Small sample size and high variability make it difficult to achieve statistical significance, even if there is a true difference. Fasting serum gastrins in adults generally fall within a narrow range of 20- 


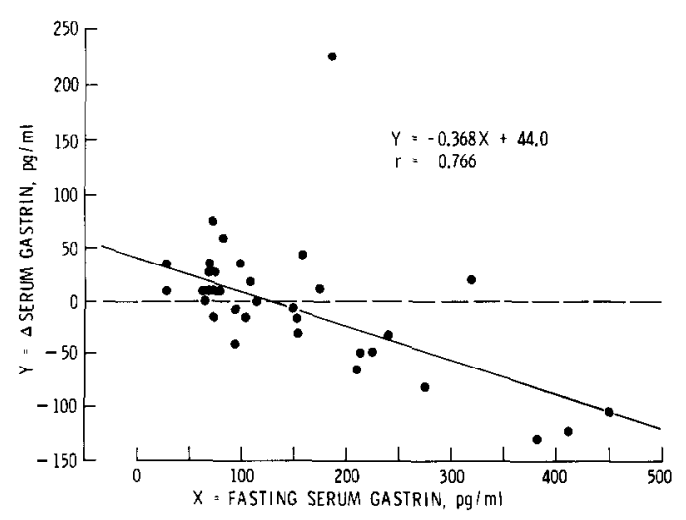

FIG. 1. Plot of the increment (positive or negative change) in serum gastrin after $60 \mathrm{cc}$ water against the fasting serum gastrin level for the combined preand postoperative group. The best fitting regression line is displayed.

$100 \mathrm{pg} / \mathrm{ml}$, and rarely exceed $200 \mathrm{pg} / \mathrm{ml}$, whereas those in infants vary widely between 20 and $500 \mathrm{pg} / \mathrm{ml}$ with $13 \%$ of one large group studied exceeding $200 \mathrm{pg} /$ $\mathrm{ml}[3]$.

The present study included a control for patient variability by analyzing the increment between fasting and postprandial serum and luminal gastrin in each patient with CHPS, both pre- and postoperatively. This protocol differs from the study of Moazam et al. [5] in that we first instilled $60 \mathrm{cc}$ of water to look at the effect of distention alone, and then $60 \mathrm{cc}$ of peptone broth to measure the effect of distention plus a protein stimulus. Moazam and her colleagues fed 11 infants with CHPS a standard protein meal (Sustagen) preoperatively and repeated the study 2 to 10 weeks postoperatively. They reported no significant differences in the mean serum gastrin level between the preoperative and postoperative groups at 15,30 , and $45 \mathrm{~min}$ following the standard meal.

Upon examining the water-distention effect on serum gastrin (Table 2), there was an apparent increase in gastrin over fasting levels preoperatively and a decrease pustoperatively. However, these incremental differences were not statistically significant when tested in a repeated measures analysis. Therefore, distention alone with $60 \mathrm{cc}$ of water appeared to have no effect on serum gastrin when compared in preoperative and postoperative groups.

Instillation of peptone broth resulted in a significantly positive gastrin increment preoperatively which was still positive but decreased after pyloromyotomy. The increased gastrin response to peptone instillation preoperatively can be explained by protein stimulation of gastrin release by the obstructed stomach. The reduced rise in serum gastrin after peptone postoperatively can be explained by the simple passage of gastric fluid through the postoperative open pylorus and the resultant diminished intensity and duration of contact of the stimulus with the gastric and duodenal mucosa. Alternatively, this finding is compatible with the activation of a duodenal inhibitory mechanism by resumption of gastric emptying.

When the serum gastrin response to water and peptone instillation was viewed as an increment with respect to fasting levels, a different pattern emerged. Eight out of nine patients with high fasting serum gastrin levels (greater than $200 \mathrm{pg} / \mathrm{ml}$ ) had a lower gastrin response to intragastric water, and thirteen out of sixteen patients with a low fasting scrum gastrin (less than $100 \mathrm{pg} / \mathrm{ml}$ ) had a higher response. This pattern ap-

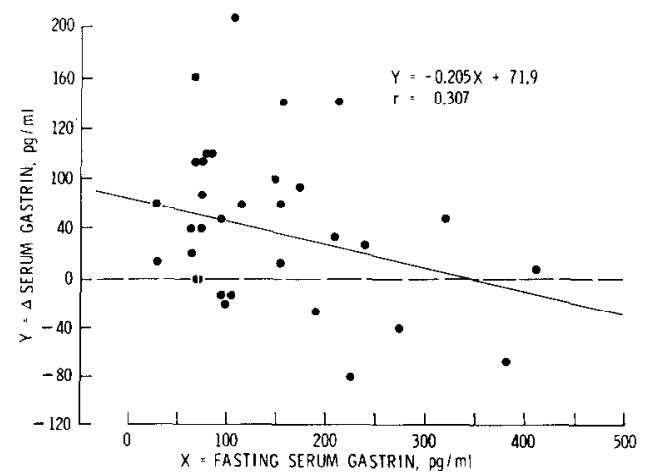

FIG. 2. Plot of the increment (positive or negative change) in serum gastrin after $60 \mathrm{cc}$ peptone against the fasting serum gastrin level for the combined preand postoperative group. The best fitting regression line is displayed. 
peared to be independent of the pyloromyotomy. When this observation was tested by a regression analysis, an inverse relationship was established between the fasting gastrin level and the water or peptone increment response according to the equation in Figs. 1 and 2; the $r$-value being 0.766 and 0.307 , respectively. After adjustment for pre- and postoperative effect and patient variation, the regression correlation between the increment and fasting level was even stronger.

From our data, therefore, it appears that intragastric water has a dual effect on serum gastrin: a rise if the fasting serum gastrin concentration is low; and a fall if the fasting serum gastrin concentration is high. Intragastric peptone generally causes a rise in serum gastrin, but less of a rise when the serum gastrin is high. This effect is independent of the pyloromyotomy. The latter finding makes it less likely that activation of a duodenal inhibitory mechanism is involved, but leaves open the possibility of an inhibitory mechanism at the gastric level.

Previous work by Fiddian-Green et al. demonstrated that intraluminal gastrin may influence gastric acid production [4]. In the present study, intraluminal gastrin levels showed no statistically significant difference when fasting preoperative levels were compared to fasting postoperative levels, or when the preoperative response to $60 \mathrm{cc}$ of water or peptone broth was compared to the postoperative response (Table 4). The large number of values at the lower sensitivity limits of the gastrin immunoassay make any conclusion from statistical analysis tentative.

Although $\mathrm{pH}$ can have an important effect on gastrin production, it does not appear to elicit a response in this particular set of experimental circumstances since no significant difference was found in $\mathrm{pH}$ pre- and postoperatively with respect to fasting, in- stillation of water, or instillation of peptone broth (Table 4).

It appears, therefore, that the serum gastrin response to intragastric instillation of water or peptone is set by the fasting level and is independent of pyloromyotomy. The relative contribution of gastric and duodenal gastrin mechanisms and the role of pyloromyotomy remain unclear.

\section{ACKNOWLEDGMENTS}

The authors wish to express their thanks to Terry Sarahan, R.N., and Robert Drongowski, M.S., for technical assistance and to Ruth Anne Hanss for typing the manuscript.

\section{REFERENCES}

1. Bleicher, M. A., Zingg, W., Shandling, B., Karl, H. W. A., and Track, N. S. Serum immunoreactive gastrin (IRG) elevation in idiopathic hypertrophic pyloric stenosis (IHPS). In Association for Academic Surgery, Abstracts for 12th Annual Meeting, 124, November 13-15, 1978.

2. Dodge, J. A., and Karim, A. A. Induction of pyloric hypertrophy by pentagastrin. Gut 17: 280, 1976.

3. Euler, A. R., Ament, M. E., and Walsh, J. H. Human newborn hypergastrinemia: An investigation of prenatal and perinatal factors and their effects on gastrin. Pediatr. Res. 12: 652, 1978.

4. Fiddian-Green, R. G., Farrell, J., Havlichek, D., Kothary, P., and Pittenger, G. A physiological role for luminal gastrin? Surgery 83: 663, 1978.

5. Moazam, F., Rodgers, B. M., Talbert, J. L., and McGuigan, J. E. Fasting and postprandial serum gastrin levels in infants with congenital hypertrophic pyloric stenosis. Ann. Surg. 188: 623, 1978.

6. Rogers, I. M., Drainer, I. K., Moore, M. R., and Buchanan, K. D. Plasma gastrin in congenital hypertrophic pyloric stenosis- $\mathbf{A}$ hypothesis disproved? Arch. Dis. Child. 50, 467, 1975.

7. Spitz, L., and Zail, S. S. Serum gastrin levels in congenital hypertrophic pyloric stenosis. $J$. Pediatr. Surg. 11: 33, 1976.

8. Wincr, B. J. Statistical Principles in Experimental Design. New York: McGraw-Hill, 1971. Pp. $796-809$.

9. Vinik, A. I. , Grant, B. J., and Novis, B. Gastrins in human antrum, duodenum, and circulation. S. Afr. Med. J. 49: 255, 1975. 